\title{
ADAM10 is essential for Notch2-dependent marginal zone B cell development and CD23 cleavage in vivo
}

\author{
David R. Gibb, ${ }^{1}$ Mohey El Shikh, ${ }^{1}$ Dae-Joong Kang, ${ }^{1}$ Warren J. Rowe, ${ }^{1}$ \\ Rania El Sayed, ${ }^{1}$ Joanna Cichy, ${ }^{2}$ Hideo Yagita, ${ }^{3}$ John G. Tew, ${ }^{1}$ \\ Peter J. Dempsey, ${ }^{4,5}$ Howard C. Crawford, ${ }^{6}$ and Daniel H. Conrad ${ }^{1}$
}

'Department of Microbiology and Immunology, Virginia Commonwealth University School of Medicine, Richmond, VA 23298 ${ }^{2}$ Faculty of Biochemistry, Biophysics, and Biotechnology, Jagiellonian University, 30-387 Krakow, Poland ${ }^{3}$ Department of Immunology, Juntendo University School of Medicine, Tokyo 113-8421, Japan

${ }^{4}$ Department of Molecular and Integrative Physiology and ${ }^{5}$ Department of Pediatrics, University of Michigan, Ann Arbor, MI 48109 ${ }^{6}$ Department of Pharmacological Sciences, Stony Brook University School of Medicine, Stony Brook, NY 11794

The proteolytic activity of a disintegrin and metalloproteinase 10 (ADAM10) regulates cell-fate decisions in Drosophila and mouse embryos. However, in utero lethality of ADAM10-Imice has prevented examination of ADAM10 cleavage events in lymphocytes. To investigate their role in B cell development, we generated B cell-specific ADAM10 knockout mice. Intriguingly, deletion of ADAM10 prevented development of the entire marginal zone $B$ cell (MZB) lineage. Additionally, cleavage of the low affinity lgE receptor, CD23, was profoundly impaired, but subsequent experiments demonstrated that ADAM10 regulates CD23 cleavage and MZB development by independent mechanisms. Development of MZBs is dependent on Notch2 signaling, which requires proteolysis of the Notch2 receptor by a previously unidentified proteinase. Further experiments revealed that Notch2 signaling is severely impaired in ADAM10-null B cells. Thus, ADAM10 critically regulates MZB development by initiating Notch2 signaling. This study identifies ADAM10 as the in vivo CD23 sheddase and an important regulator of $B$ cell development. Moreover, it has important implications for the treatment of numerous CD23- and Notch-mediated pathologies, ranging from allergy to cancer.

CORRESPONDENCE

Daniel H. Conrad:

dconrad@vcu.edu

Abbreviations used: ADAM, a disintegrin and metalloproteinase; AMCA, aminomethylcoumarin acetate; B-CLL, B cell chronic lymphocytic leukemia; Dll1, Delta-like 1; Dtx1, deltex-1; FDC, follicular DC; FO, follicular; Hes, hairy enhancer of split; mCD23, membranebound CD23; MEF, mouse embryonic fibroblast; MMP, matrix metalloproteinase; MOMA-1, metallophilic macrophage marker 1 ; MZB, marginal zone B cell; NICD, Notch intracellular domain; NRR, negative regulatory region; PLN, peripheral LN; PMZB, pre-MZB; sCD23, soluble CD23; T1 and T2, transitional type 1 and 2 , respectively.
A disintegrin and metalloproteinases (ADAMs) are zinc-dependent proteinases related to matrix metalloproteinases (MMPs). The combination of metalloproteinase and disintegrin domains is characteristic of all ADAMs. Although 38 ADAMs have been identified, ADAM10 has emerged as one of several members that regulates cell processes by cleaving or shedding extracellular domains of numerous transmembrane receptors and ligands. ADAMs can also activate vital signaling pathways that require regulated intramembrane proteolysis of receptor-ligand complexes. Studies in Drosophila and in vitro experiments using ADAM10-deficient mouse embryonic fibroblasts (MEFs) and protease inhibitors have generated a growing list of putative ADAM10 substrates, including the ErbB2 receptor, several ErbB ligands, Notch receptors, Delta-like 1 (Dl11), ephrins, FasL, the

P.J. Dempsey, H.C. Crawford, and D.H. Conrad contributed equally to this paper.
IL-6 receptor, CXCL-16, and CD23 (Blobel, 2005; Crawford et al., 2009). However, in utero lethality of ADAM10 $0^{-/-}$mice has hindered examination of these cleavage events in vivo (Hartmann et al., 2002).

ADAM-mediated cleavage of Notch receptors initiates an irreversible signaling cascade that dictates cell-fate processes (Kopan and Ilagan, 2009). Recently, many studies have described the importance of Notch signaling in lymphocyte development (Tanigaki and Honjo, 2007). However, as described by Kopan and Ilagan (2009), the identity of the proteinase that initiates Notch signaling in mammalian cells is the subject of great controversy. Initially, two independent groups using in vitro models concluded that ADAM17 (TNF-converting enzyme) initiates

0 2010 Gibb et al. This article is distributed under the terms of an AttributionNoncommercial-Share Alike-No Mirror Sites license for the first six months after the publication date (see http://www.jem.org/misc/terms.shtml). After six months it is available under a Creative Commons License (Attribution-NoncommercialShare Alike 3.0 Unported license, as described at http://creativecommons.org/ licenses/by-nc-sa/3.0/). 
Notch1 signaling by cleaving Notch1 in monocytic precursors and MEFs (Brou et al., 2000; Mumm et al., 2000). Thus, ADAM17 is often referenced in the literature as the relevant proteinase that initiates Notch signaling in lymphocytes (Radtke et al., 2004). However, generation of ADAM17 mutant and conditional knockout mice has not resulted in Notch-related phenotypes in lymphocytes (Li et al., 2007; Le Gall et al., 2009). In contrast, ADAM10-deficient mouse embryos display many features also observed in nonviable Notch1 $1^{-/-}$embryos (Swiatek et al., 1994; Hartmann et al., 2002). To further complicate this issue, multiple in vitro studies have demonstrated that ADAM17 cleaves numerous ADAM10 substrates (Hinkle et al., 2004; Sahin et al., 2004), whereas ADAM10 can cleave many ADAM17 substrates from ADAM17 ${ }^{-/-}$MEFs (Le Gall et al., 2009). Most recently, two groups using ADAM10-/- $\mathrm{MEF}$ concluded that ADAM10 mediates ligand-dependent Notch1 cleavage, whereas other proteases regulate ligand-independent cleavage (Bozkulak and Weinmaster, 2009; van Tetering et al., 2009). Finally, Tian et al. (2008) reported that ADAM10 conditional knockout thymocytes have altered development and impaired Notch1 signaling. However, the authors acknowledged that many differences exist between Notch1and ADAM10-deficient thymocytes (Wolfer et al., 2002; Tian et al., 2008), and concluded that ADAM17 plays a compensatory role in Notch1 cleavage (Tian et al., 2008). These reports indicate that ADAM family members perform overlapping or compensatory functions.

Four Notch receptors, Notch1-4, are expressed in humans and rodents (Kopan and Ilagan, 2009). However, previous studies have only addressed Notch1 activation. It is unclear whether conclusions drawn from studies on Notch1 cleavage can be generalized to other Notch receptors. Specifically, the Notch1 cleavage site recognized by ADAMs is not present in mouse Notch2 (Brou et al., 2000). Additionally, the phenotype of ADAM10 ${ }^{-/-}$embryos was strikingly similar to that of Notch1,4 double knockout embryos (Hartmann et al., 2002) but quite distinct from features of nonviable Notch2 embryos (Hamada et al., 1999). To date, the role of ADAMs in Notch2 cleavage has not been examined.

Notch2 signaling regulates B cell development (Tanigaki and Honjo, 2007). In contrast to T cells, naive B cells preferentially express Notch2, and express extremely low levels of Notch1, Notch3, and Notch4 (Saito et al., 2003; Santos et al., 2007; Moriyama et al., 2008). As immature B cells enter the spleen as transitional cells, they either differentiate into follicular (FO) B cells or cells of the marginal zone B cell (MZB) lineage. Notch2 signaling is required for development of the MZB lineage (Saito et al., 2003), which initiates critical immune responses to bloodborne infections and performs important roles in antigen transport and presentation (Pillai et al., 2005). During MZB development, the Notch2 heterodimer binds ligands such as Dll1 present on stromal and antigen-presenting cells (Hozumi et al., 2004). Binding initiates proteolytic processing of the receptor by an unidentified metalloproteinase, which leads to the release of the Notch intracellular domain (NICD) that translocates to the nucleus and binds the transcription factor RBP-Jк. This activated complex drives the expression of Notch2 target genes, including complement receptors (CD21/35), deltex-1 (Dtx1), hairy enhancer of split 1 (Hes1), and Hes5 (Saito et al., 2003; Tanigaki and Honjo, 2007). Deletion of Dll1 from nonhematopoietic cells (Hozumi et al., 2004), or Notch2 or RBP-Jк from B cells profoundly inhibits MZB development (Tanigaki et al., 2002; Saito et al., 2003). Many other regulators of Notch2 signaling have been identified. However, the metalloproteinase necessary for initiating signaling is unknown, and a role for ADAM10 in B cell development or Notch2 signaling has not been examined.

To date, the only putative ADAM10 substrates expressed by B cells are the low affinity IgE receptor, CD23 (Weskamp et al., 2006; Lemieux et al., 2007), and FasL (Schulte et al., 2007). CD23, expressed on mouse B cells and follicular DCs (FDCs), is a known regulator of allergic and inflammatory responses. Catabolic shedding of CD23 from the cell surface is an important processing event that regulates its function (Conrad et al., 2007; Gould and Sutton, 2008). CD23 cleavage may also regulate the development of MZBs. Precursors of MZBs, including transitional type 2 (T2) B cells and pre-MZBs (PMZBs), down-regulate surface expression of CD23 as they differentiate into MZBs (Pillai et al., 2005). However, the role of CD23 cleavage in B cell development has not been examined.

Two independent groups have demonstrated the ability of ADAM10 to cleave CD23 in vitro (Weskamp et al., 2006; Lemieux et al., 2007). These studies generated intriguing questions about the role of ADAM10 in the regulation of CD23-mediated immune responses. However, earlier in vitro experiments demonstrated the ability of ADAM8 and ADAM15 to cleave CD23 (Fourie et al., 2003). In addition, a recent study determined that MMP-9 is the principal sheddase of CD23 in LPS-treated mice (Jackson et al., 2009). Given that many ADAM substrates, including Notch1 and CD23, can be cleaved by multiple proteases in vitro, the physiological relevance of ADAM10-mediated cleavage in $\mathrm{B}$ cells is unclear. This requires examination of ADAM10null B cells from B cell-specific knockout mice.

Given the importance of ADAM10 in embryonic development and its potential role in thymocyte development, we formally tested the hypothesis that ADAM10 regulates B cell development. Generation of B cell-specific knockout mice revealed that ADAM10 is a critical regulator of Notch2 signaling, and as a result, it is essential for the development of the entire MZB lineage. Additionally, we report that ADAM10 is the primary sheddase of CD23 in vivo. Moreover, despite reports of compensatory roles for ADAMs in vitro and in thymocytes, other proteases did not compensate for the lack of ADAM10 activity in B cells.

\section{RESULTS}

Generation of B cell-specific ADAM10 knockout mice

To determine the role of ADAM10 in B cell development, we generated B cell-specific ADAM10 knockouts 
by crossing mice containing loxP sites surrounding exon 9 of ADAM10 (ADAM10 ${ }^{\Delta / \Delta}$ ) with CD19cre knockin animals (Fig. S1; Rickert et al., 1997). PCR analysis of DNA isolated from $\mathrm{B} 220^{+}$and $\mathrm{B} 220^{-}$splenocytes indicated that cre-mediated recombination of exon 9 occurs in an efficient B cell-specific manner in ADAM10 ${ }^{\Delta / \Delta} \mathrm{CD} 19 \mathrm{cre}^{+/-}$ (ADAM10 ${ }^{\Delta / \Delta} \mathrm{Cre}^{+/-}$) mice (Fig. 1 A). To better assess the sensitivity and cell specificity of recombination, we generated ADAM10 ${ }^{\Delta / \Delta} \mathrm{CD} 19 \mathrm{cre}^{+/-} \mathrm{R} 26 \mathrm{R}-\mathrm{EYFP}^{+}\left(\mathrm{ADAM} 10^{\Delta / \Delta}\right.$ $\mathrm{cre}^{+/-} \mathrm{EYFP}^{+}$) mice that express the EYFP transgene after cre-mediated recombination (Srinivas et al., 2001). Deletion of exon 9, which encodes the $\mathrm{Zn}$-binding domain of the protease active site, produces a frameshift mutation that interrupts transcription. Thus, recombination of ADAM10 in $\mathrm{ADAM}_{10} 0^{\Delta / \Delta} \mathrm{Cre}^{+/-} \mathrm{EYFP}^{+}$mice resulted in the loss of ADAM10 mRNA and protein expression in $\mathrm{EYFP}^{+}$ cells, including FO and T1 spleen B cells (Fig. 1, B and C). Because ADAM10 surface expression is only detectable on EYFP $^{-}$cells (unpublished data), EYFP is a reliable reporter for ADAM10 deletion. Recombination detected by EYFP expression occurs in 87 and $95 \%$ of $\mathrm{B} 220^{+} \mathrm{B}$ cells in the spleen and peripheral LNs (PLNs), respectively (Fig. S2 A). In addition, 96 and $98 \%$ of $\mathrm{EYFP}^{+}$cells from the spleen and PLNs express B220. This data combined with the lack of EYFP expression by B220- cells and Thy $1^{+}$(CD90) $\mathrm{T}$ cells indicates that recombination occurs exclusively in B lymphocytes (Fig. S2 B).

\section{ADAM10 is indispensable for MZB development}

Because reductions in ADAM10 activity modestly impair thymocyte development (Manilay et al., 2005; Tian et al., 2008), we examined the role of ADAM10 in B cell development. Early development was not altered in ADAM10 ${ }^{\Delta / \Delta} \mathrm{Cre}^{+/-}$ mice. The percentage of pro- and pre-B cells $\left(\mathrm{B} 220^{+} \mathrm{IgM}^{-}\right)$ and immature $\mathrm{B}$ cells $\left(\mathrm{B}_{2} 20^{+} \mathrm{IgM}^{+}\right)$in the bone marrow did not differ between ADAM10 ${ }^{\Delta / \Delta}$ and ADAM10 $0^{\Delta / \Delta} \mathrm{Cre}^{+/-}$mice (Fig. S3 A). Additionally, deletion of ADAM10 did not alter the level of B1 cells in the peritoneum (Fig. S4). In contrast, further B cell development in the spleen was drastically altered. Most interestingly, MZBs (CD23 low/-CD21/35 ${ }^{\text {hi }}$ gM $^{\text {hi }}$ ) were not present in $\mathrm{ADAM} 10^{\Delta / \Delta} \mathrm{Cre}^{+/-} \mathrm{EYFP}^{+}$mice (Fig. 2, B and D). Immunohistochemical staining of spleen cryosections revealed a complete absence of IgM $^{\text {hi }}$-expressing MZBs surrounding the marginal sinus, labeled with the metallophilic macrophage marker 1 (MOMA-1; Fig. 2 E). Additionally, development of precursors to MZBs, (CD23 ${ }^{\text {int } / \mathrm{hi}} \mathrm{CD} 21 /$ 35 $5^{\text {hi }}$ gM $^{\text {hi }}$; Fig. 2, A and D), was severely abrogated. Thus, there was also a dramatic decrease in CD1d ${ }^{\text {hi }}$ CD9hi $\mathrm{B}$ cells, which include PMZB and MZB populations (Fig. 2 C).

The development of transitional $\mathrm{B}$ cells was moderately altered by ADAM10 deletion. The level of T2 B cells $\left(\mathrm{CD} 23^{+} \mathrm{CD} 21 / 35^{\text {int }} \mathrm{AA} 4.1^{+}\right)$was significantly decreased in knockout mice (Fig. 2 D and Fig. S5), whereas the percentage of $\mathrm{T} 1$ cells $\left(\mathrm{CD} 23^{\text {low/-CD }} 21 / 35^{\text {low }} \operatorname{IgM}^{\text {hi }}\right.$ ) was modestly elevated compared with heterozygotes (Fig. 2, B and D).
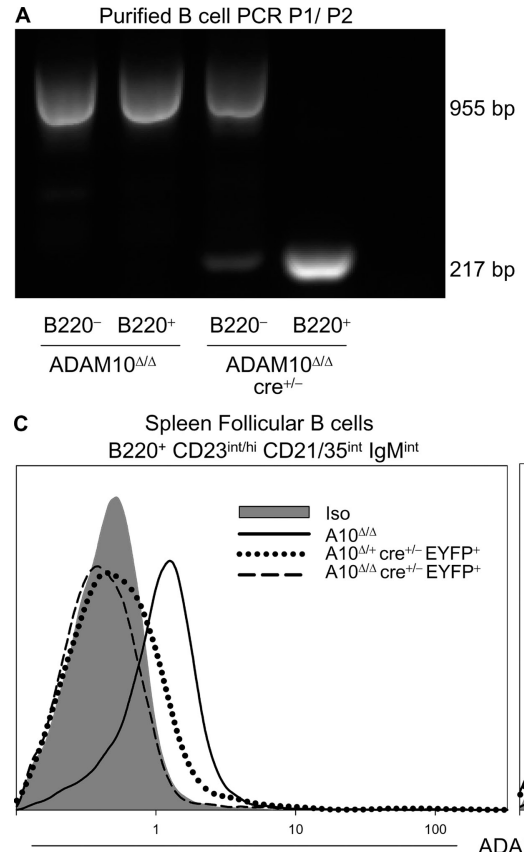

B Purified B cell RT-PCR

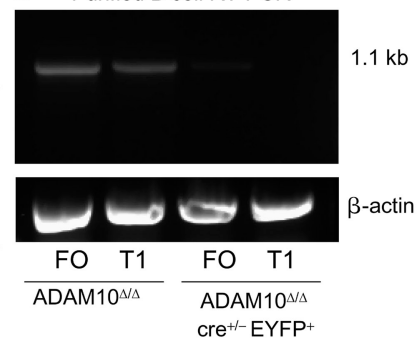

Spleen Transitional $1 \mathrm{~B}$ cells $\mathrm{B} 220^{+} \mathrm{CD} 23^{\text {low } /-} \mathrm{CD} 21 / 35^{\text {low }}$ IgM ${ }^{\mathrm{hi}}$

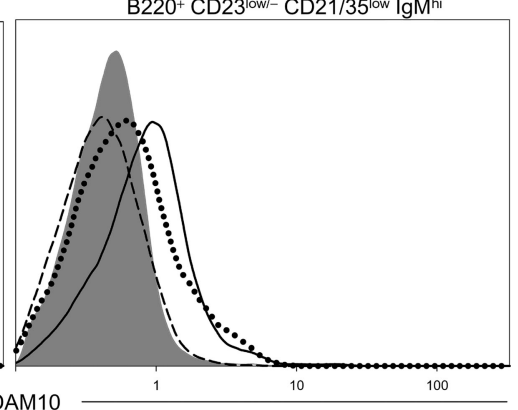

Figure 1. ADAM10 ${ }^{\Delta / \Delta C D 19} \mathrm{cre}^{+/-}$mice are B cell-specific ADAM10 knockouts. (A) PCR products for exon 9 of ADAM10 performed on isolated DNA, using primers P1 and P2 (Fig. S1). Spleen B220+ B cells and B220- non-B cells from the indicated mice were sorted via FACS. 955- and 217-bp bands represent full-length and recombined ADAM10, respectively. (B) RT-PCR for ADAM10 mRNA isolated from F0 and T1 spleen B cells. F0 B cells iden-

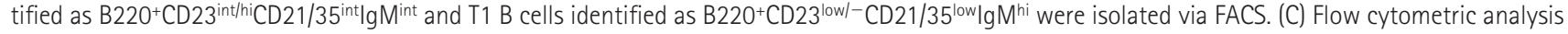
of ADAM 10 expression on the surface of FO and T1 spleen B cells from the indicated mice. Sorted and analyzed cells from EYFP+ mice were identified as EYFP+ instead of $\mathrm{B}^{2} 20^{+}$. Data are representative of three independent experiments. 

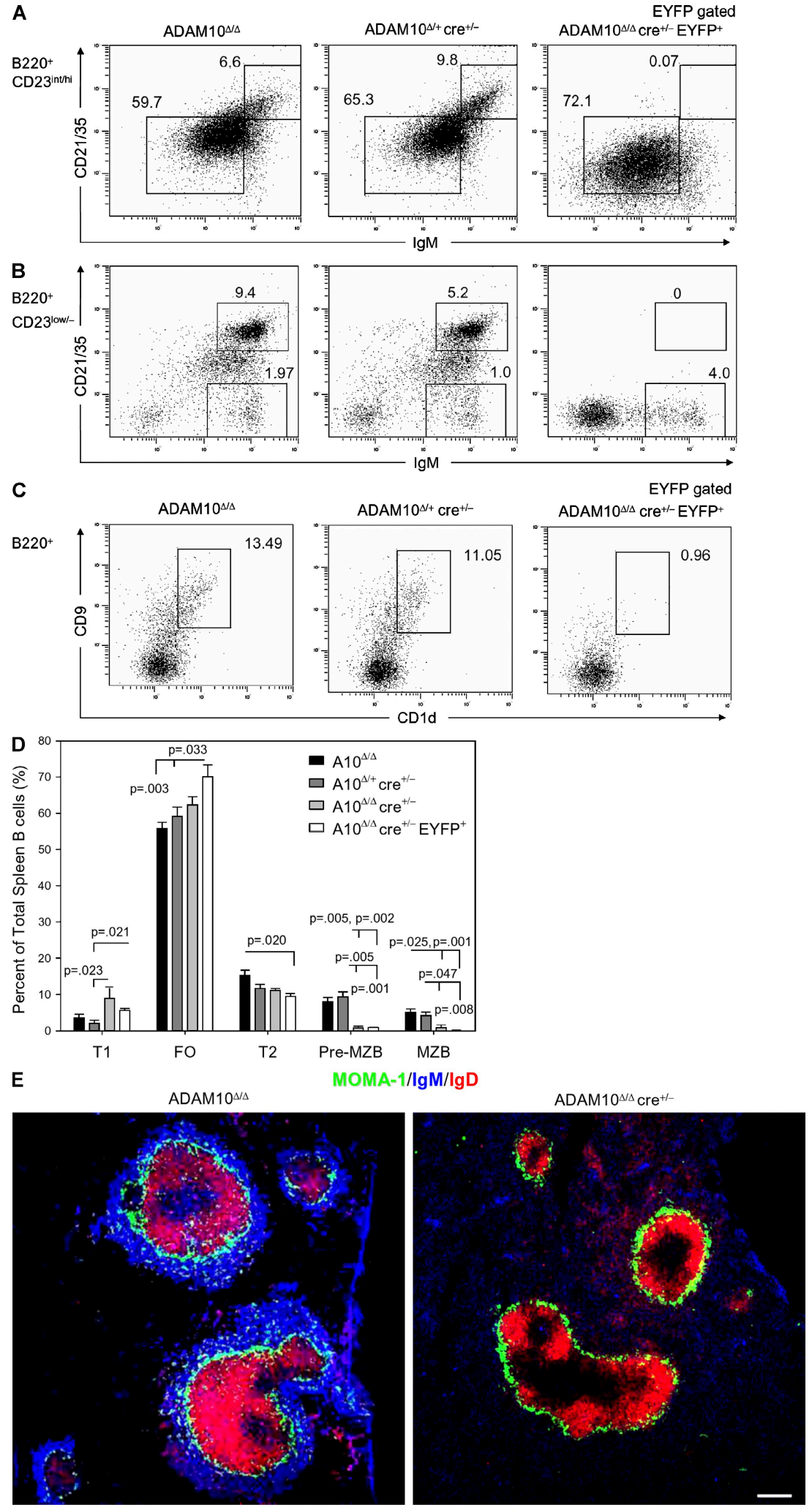

Figure 2. ADAM10 is essential for MZB lineage development. (A and B) Flow cytometric analysis of spleen $B$ cells labeled for CD21/35 and IgM expression, gated on (A) B220 ${ }^{+}$CD23 int/hi and (B) B220 ${ }^{+}$CD23 ${ }^{\text {low } /-}$ cells. (C) Analysis of PMZBs and MZBs labeled for CD1d and CD9 expression. Flow cytometric plots in A-C are representative of six experiments. (D) Levels of B cell subsets are expressed as the percentage of total spleen $B$ cells $(n=6$ except for T2 cells $[n=3])$. Data are cumulative from six independent experiments for all subsets except for T2 cells, which are cumulative from three 
Finally, although the percentage of total B cells in the spleen was not altered (Fig. S3 B), levels of FO B cells (CD23 ${ }^{\text {int/ }}$ ${ }^{\text {hi }} \mathrm{CD} 21 / 35^{\text {int }} \operatorname{IgM}^{\text {int }}$ ) were significantly elevated in ADAM10 ${ }^{\Delta / \Delta}$ $\mathrm{cre}^{+/-} \mathrm{EYFP}^{+}$mice compared with controls (Fig. 2, A and D). The increase in FO B cells and the reduction in PMZBs indicate a developmental defect rather than impaired maintenance of the MZB population. Thus, ADAM10 is essential for development of the entire MZB lineage.

\section{ADAM10 is the primary sheddase of CD23 in vivo}

Precursors of MZBs down-regulate surface expression of CD23 as they differentiate (Pillai et al., 2005). Given that in vitro studies have demonstrated the ability of ADAM10 to cleave CD23 (Weskamp et al., 2006; Lemieux et al., 2007), we considered that ADAM10 may be required for in vivo CD23 cleavage, which may regulate $\mathrm{MZB}$ development. To determine whether ADAM10 cleaves CD23 in vivo, we examined the levels of membrane-bound CD23 (mCD23) on B cells and soluble CD23 (sCD23) in the serum of ADAM10 ${ }^{\Delta / \Delta} \mathrm{Cre}^{+/-}$and control mice. Flow cytometric and immunohistochemical analyses revealed that deletion of ADAM10 resulted in a dramatic increase in mCD23 (Fig. 3 and Fig. S6). mCD23 was significantly elevated on FO B cells, total spleen B cells, and PLN B cells (Fig. 3, A and B; and Fig. S6, A and B). Immunohistochemical labeling illustrates this profound increase on $\mathrm{B}$ cells within the spleen follicle, surrounded by the marginal sinus, labeled with MOMA-1 (Fig. 3 C). Deletion of ADAM10 from B cells also significantly reduced the amount of sCD23 detected in the serum of ADAM $10^{\Delta / \Delta} \mathrm{Cre}^{+/-}$mice by $69.1 \%$ compared with ADAM10 ${ }^{\Delta / \Delta}$ controls (Fig. 3 D). Importantly, deletion of ADAM10 did not alter CD23 mRNA levels (Fig. S6 C). Thus, ADAM10 clearly regulates CD23 surface expression through posttranslational proteolysis. These data indicate that ADAM10 is the primary sheddase of CD23 in vivo.

Although this result demonstrates that other proteases do not compensate for the absence of ADAM10, a low level of sCD23 was measured in the serum of ADAM10 ${ }^{\Delta / \Delta} \mathrm{cre}^{+/-}$mice. This may have been the result of incomplete cre-mediated recombination in B cells (Fig. S2 A), trans-cleavage of CD23 by secreted proteases or ADAM10-expressing non-B cells, or cleavage of mCD23 from FDCs. To evaluate cleavage in the complete absence of ADAM10, we purified $\mathrm{EYFP}^{+} \mathrm{FO} B$ cells from spleens of $\mathrm{ADAM} 10^{\Delta / \Delta} \mathrm{Cre}^{+/-} \mathrm{EYFP}^{+}$mice. These isolated cells and FO B cells from control mice were stimulated with CD40L and IL-4 to promote mCD23 expression before the addition of the anti-CD23 stalk antibody, 19G5, or an isotype control antibody, $\mathrm{COH} 2$. Antibody binding to the coiledcoil stalk region of CD23 disrupts the homotrimeric structure of mCD23 and promotes mCD23 cleavage (Ford et al., 2006). As expected, 19G5 reduced mCD23 levels on FO B cells isolated from ADAM10 ${ }^{\Delta / \Delta}$ and ADAM10 ${ }^{\Delta /+} \mathrm{Cre}^{+/-}$mice (Fig. $3 \mathrm{E}$ ), and increased sCD23 levels in culture supernatants (Fig. 3 F). In contrast, 19G5 did not influence the level of mCD23 on purified ADAM10-null B cells and did not enhance release of sCD23 into supernatants. This result further demonstrates that cleavage of CD23 from ADAM10-null B cells is severely impaired.

\section{CD23 expression does not regulate MZB development}

Deletion of ADAM10 had profound effects on CD23 cleavage and MZB lineage development. Thus, we examined the role of CD23 in MZB development. Levels of MZBs in wild-type C57BL/6, CD23 transgenic (Payet et al., 1999), CD23 ${ }^{-/-}$(Yu et al., 1994), and ADAM10 ${ }^{\Delta / \Delta} \mathrm{Cre}^{+/-} \mathrm{EYFP}^{+}$mice were determined by labeling IgM, IgD, and CD21/35 on splenocytes. $\mathrm{IgM}^{\text {hi }} \mathrm{IgD}^{\text {low }}$ spleen $\mathrm{B}$ cells are a heterogeneous population including T1 cells and MZBs. However, T1 cells and MZBs are CD21/35 $5^{\text {low }}$ and $C D 21 / 35^{\text {hi }}$, respectively. Flow cytometric analysis demonstrated that the percentage of $\operatorname{IgM}{ }^{\text {hi }} \operatorname{IgD}{ }^{\text {low }} \mathrm{CD} 21 /$ $35^{\text {hi }} \mathrm{MZBs}$ in CD23 transgenic and $\mathrm{CD} 23^{-1-}$ spleens did not differ from C57BL/6 mice. In contrast, similarly defined cells were not present in ADAM10 ${ }^{\Delta / \Delta} \mathrm{Cre}^{+/-} \mathrm{EYFP}^{+}$spleens (Fig. 4). Thus, ADAM10 mediates MZB development by a mechanism independent of CD23 cleavage.

\section{ADAM10 initiates Notch2 signaling}

Previous studies demonstrated that ADAM10-deficient mouse embryos resemble Notch1,4-deficient embryos (Swiatek et al., 1994; Hartmann et al., 2002), and Notch1 signaling is altered in ADAM10-null thymocytes (Tian et al., 2008). Although Notch1, Notch3, and Notch4 are minimally expressed by naive mouse B cells, signaling through the Notch2 receptor is critical for MZB development (Saito et al., 2003; Santos et al., 2007; Moriyama et al., 2008). Thus, we considered the possibility that ADAM10 is required for Notch2 signaling. Interestingly, ADAM10 and Notch2 are both preferentially expressed on cells of the MZB lineage, including PMZBs and MZBs (Fig. S7, A and B). ADAM-mediated cleavage of Notch receptors initiates the release of the NICD that mediates downstream signaling. However, rapid degradation prevents detection of physiological levels of NICD (Kopan and Ilagan, 2009). Thus, to determine if ADAM10 is required for Notch2 signaling in B cells, we examined the expression of Notch2 target genes, including CD21/35, Hes1, Hes5, and Dtx1.

Multiple reports have demonstrated that Notch signaling enhances expression of CD21/35 (Strobl et al., 2000; Makar et al., 2001). By generating Notch2 ${ }^{\mathrm{f} /-}$ CD $19 \mathrm{cre}^{+/-}$mice, Saito et al. (2003) demonstrated that Notch2 signaling may regulate CD21/35 expression in B cells. Deletion of Notch2 resulted

independent experiments. In A-D, FO and T1 cells were identified as in Fig. 1. MZBs, T2 cells, and PMZBs were identified as follows: T2 cells, B220+CD23+CD21/

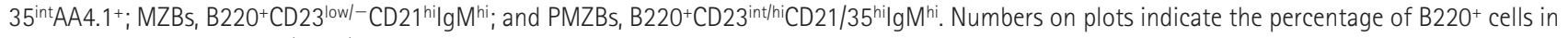
boxes. Cells from ADAM $10^{\Delta / \Delta} \mathrm{Cre}^{+/-E Y F P+}$ mice were identified as EYFP+ instead of B220+. Error bars represent the SEM between samples. (E) Immunohistochemical labeling of spleen follicles for MOMA-1, IgM, and IgD expression. Data are representative of three independent experiments. Bar, $100 \mu \mathrm{m}$. 
in a significant decrease in CD21/35 surface expression. Our analysis of ADAM10 ${ }^{\Delta / \Delta} \mathrm{Cre}^{+/-} \mathrm{B}$ cells revealed that ADAM10 regulates CD21/35 expression in a remarkably similar manner. Deletion of ADAM10 resulted in a 61 and $67 \%$ reduction in CD21/35 expression on the surface of spleen FO B cells (Fig. 5,
A and B) and PLN B cells, respectively (Fig. S8). Immunohistochemical staining of spleen follicles verified that the reduced expression was specific to B cells. Although CD21/35 labeling of $\mathrm{ADAM} 10^{\Delta / \Delta} \mathrm{Cre}^{+/-}$follicles was generally diminished, we observed concentrated areas of intense staining (Fig. 5 E).

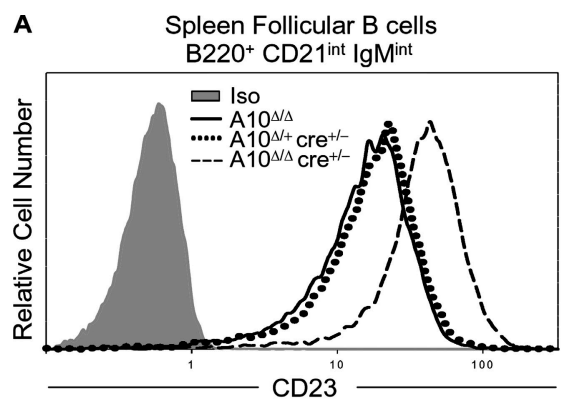

C
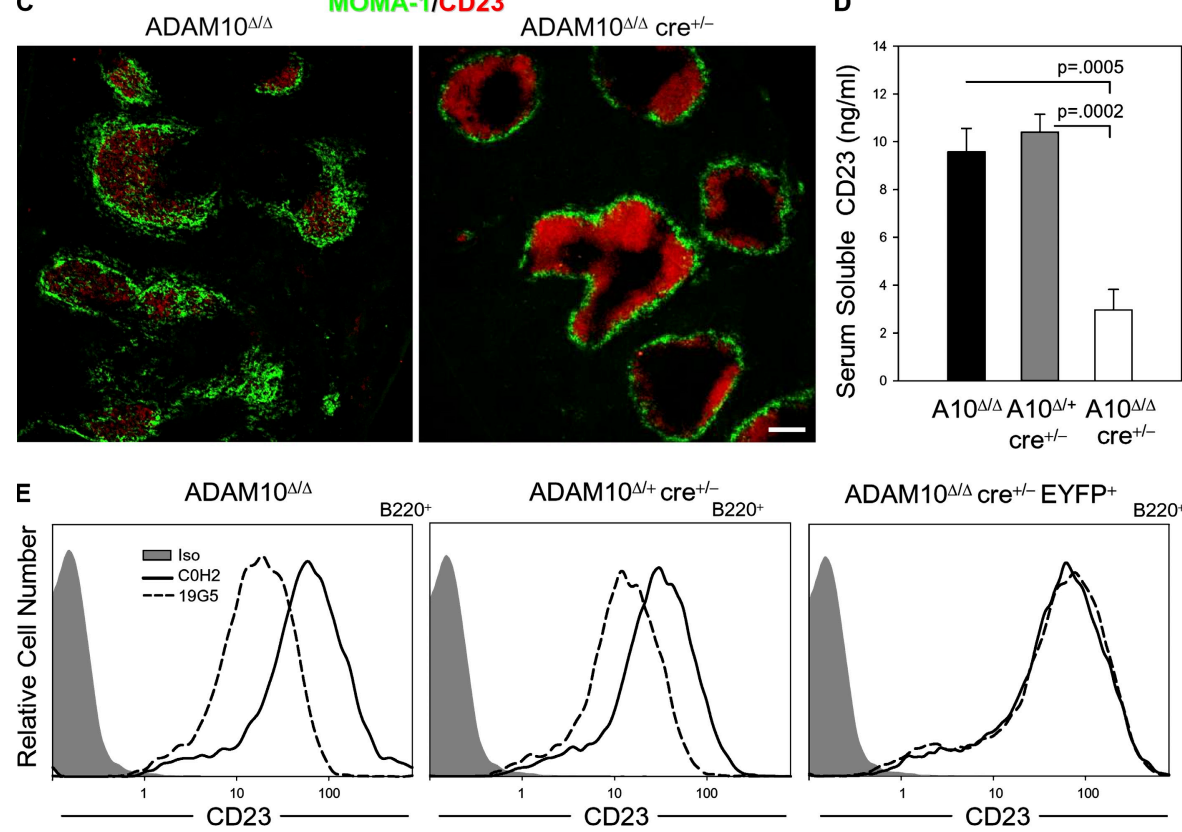

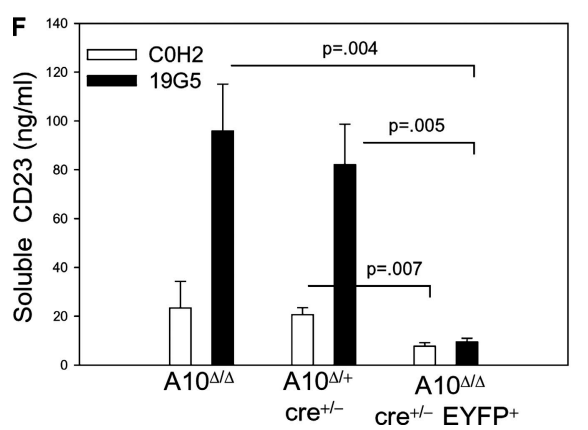

Figure 3. ADAM10 is the primary in vivo sheddase of CD23. (A) Cell-surface expression of CD23 on spleen FO B cells from the indicated mice. Data are representative of six independent experiments. (B) Mean fluorescent intensity (MFI) of $m$ CD23 expression by FO B cells (B220+CD21 intlgMint; $n=6)$. (C) Immunohistochemical staining of spleen cryosections from the indicated mice. CD23-PE and MOMA-1-FITC labeling of metallophilic macrophages in the marginal sinus surrounding spleen follicles is shown. Data are representative of three independent experiments. Bar, $100 \mu$ m. (D) Serum sCD23 levels measured by ELISA $(n=4)$. (E and F) Cleavage of CD23 on FO B cells treated with $19 \mathrm{G} 5$ or COH2 ex vivo. FO B cells isolated from spleens as in Fig. 1 B were cultured for $24 \mathrm{~h}$ with CD40L, IL-4, and 8:A3 to elevate mCD23 levels before washing and culture with $100 \mu \mathrm{g} 19 \mathrm{G} 5 \mathrm{or} \mathrm{COH} 2$ with fresh cytokines. Cells and supernatants were collected $17 \mathrm{~h}$ later and analyzed for $\mathrm{mCD} 23$ expression via flow cytometry (E) and sCD23 via ELISA (F), respectively $(n=4)$. Data in D-F are representative and cumulative from four independent experiments. Error bars represent the SEM between samples. 
Labeling of these areas with anti-IgG to identify immune complexes on FDCs revealed that CD21/35 expression on FDCs was intact in ADAM $10^{\Delta / \Delta} \mathrm{Cre}^{+/-}$mice (Fig. 5 F). Additionally, the levels of soluble CD21/35 in serum were also significantly lower than controls (Fig. 5 C), demonstrating that all forms of B cell CD21/35 were reduced. Reductions in CD21/35 mRNA levels in sorted spleen B cells established that the suppressed protein expression was the result of diminished transcriptional activation or mRNA stability in ADAM $10^{\Delta / \Delta} \mathrm{Cre}^{+/-}$B cells (Fig. 5 D).

The absence of MZB development and the diminished expression of complement receptors in ADAM $10^{\Delta / \Delta} \mathrm{Cre}^{+/-} \mathrm{EYFP}^{+}$ mice indicate that ADAM10 may be required for Notch2 signaling. To further investigate this hypothesis, we measured the expression of the canonical Notch targets Dtx1, Hes1, and Hes5 in sorted spleen B cells. Real-time PCR analysis revealed that expression levels of the Notch2-selective target, Dtx1, and the general Notch receptor targets, Hes1 and Hes5, were all significantly reduced in $\mathrm{EYFP}^{+}$spleen $\mathrm{FO} \mathrm{B}$ cells from ADAM10 ${ }^{\Delta / \Delta} \mathrm{Cre}^{+/-} \mathrm{EYFP}^{+}$mice compared with ADAM10 $0^{\Delta / \Delta}$ and ADAM $10^{\Delta /+} \mathrm{Cre}^{+/-}$controls (Fig. 6, A-C). Additionally, Dtx1 and Hes1 expression in T1 B cells was significantly suppressed in the absence of ADAM10. Expression levels of Notch targets in B cells from ADAM $10^{\Delta /+} \mathrm{Cre}^{+/-}$heterozygous mice formed a consistent trend of lower expression compared with ADAM10 $0^{\Delta / \Delta}$ mice. ADAM10 ${ }^{\Delta /+} \mathrm{Cre}^{+/-} \mathrm{T} 1$ cells and MZBs expressed significantly less Hes1 and Dtx1, respectively. These results clearly demonstrate that deletion of ADAM10 profoundly impairs Notch signaling in B cells. Although signaling through multiple Notch receptors can induce expression of Hes1 and Hes5, expression of Dtx1 and CD21/35 is tightly reg- ulated by Notch2 signaling (Saito et al., 2003). Thus, ADAM10 regulates signaling through the Notch2 receptor.

We considered the possibility that ADAM10 may be required for the expression of critical Notch2 signaling components, including the Notch2 receptor or the transcription factor RBP-Јк. However, Notch2 and RBP-Jк expression were not altered in ADAM10-null B cells (Fig. S7 C and not depicted). In addition, engagement of the Notch2 ligand, Dll1, expressed on spleen stromal cells, antigen-presenting cells, and FDCs (Yoon et al., 2009) is also required for Notch2 signal activation and MZB development (Hozumi et al., 2004). Impaired interaction between ADAM10-null $B$ cells and Dll1-expressing cells in the spleen could also result in decreased expression of Notch2 targets in primary B cells. To directly determine whether ADAM10-null B cells are capable of responding to Dll1, purified FO B cells were stimulated in the presence of an Fc-Dll1 chimera or control mouse IgG. Fc-D1l1 stimulated expression of Dtx1, Hes1, and Hes5 in control B cells cultured for 36, 60, or 84 h. Peak expression was observed at $60 \mathrm{~h}$. In contrast, ADAM10-null B cells clearly failed to respond to Fc-Dll1 stimulation at any time point (Fig. $6 \mathrm{D}$ and not depicted). Thus, B cells lacking ADAM10 are unable to respond to the primary Notch2 ligand that induces MZB development. Collectively, these data confirm that ADAM10 is required for initiating Notch2 signaling in B cells.

\section{DISCUSSION}

In this study, we formally tested the hypothesis that ADAM10 regulates $\mathrm{B}$ cell development. The generation and analysis of B cell-specific ADAM10 knockout mice revealed that
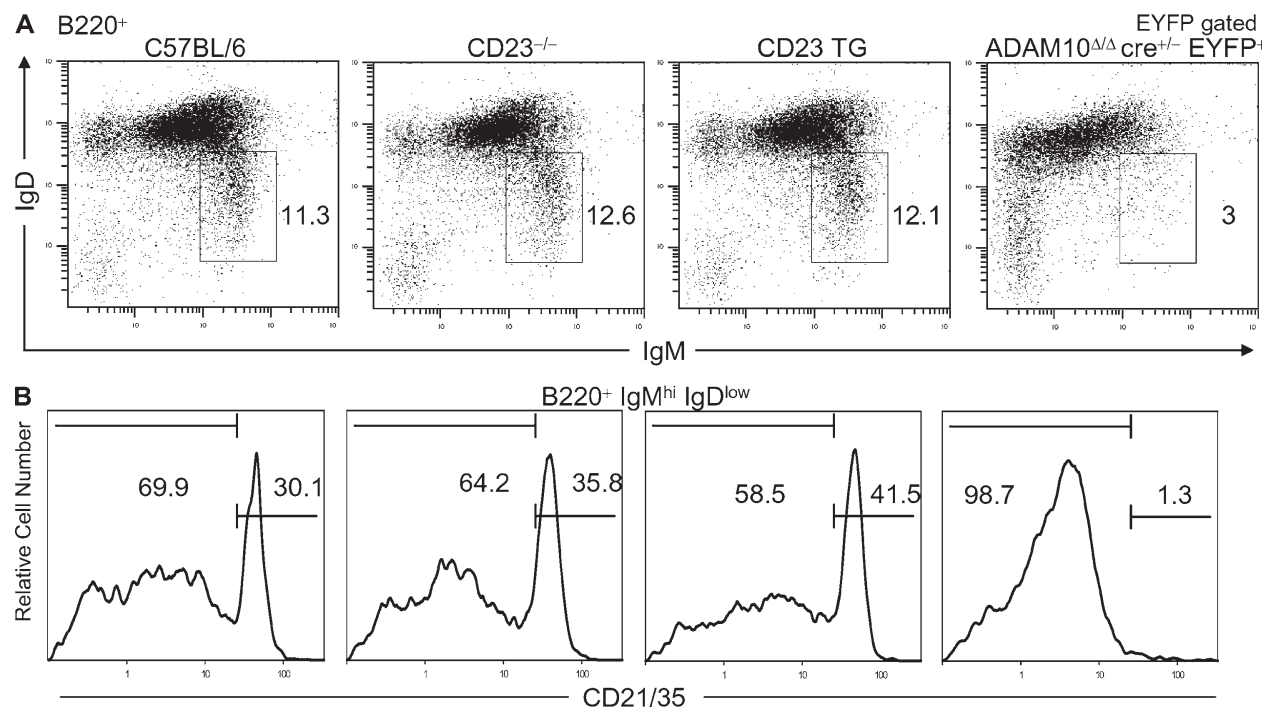

Figure 4. CD23 expression does not regulate MZB development. Flow cytometric analysis of spleen $B$ cells from $C 57 B L / 6, C D 23^{-1-}, C D 23$ transgenic (TG), and $A D A M 10^{\Delta / \Delta} \mathrm{Cre}^{+/-E Y F P+}$ mice labeled for surface expression of $\operatorname{lgM}, \lg D$, and $C D 21 / 35$. (A) Numbers indicate the percentage of $B 220^{+}$or

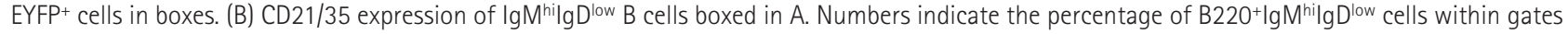

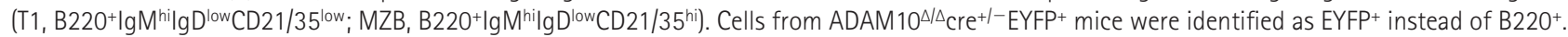
Data are representative of three independent experiments. 
ADAM10 critically regulates development of the entire MZB lineage by initiating Notch2 signaling.

The rate-limiting step in Notch2 signaling is cleavage within the receptor's negative regulatory region (NRR) located in the membrane-proximal portion of the extracellular domain. The structure of the NRR prevents ligand-independent Notch cleavage. Mutations in the NRR can allow cleavage in the absence of ligand, leading to constitutive Notch signaling. In the case of Notch1, this leads to the formation of T cell acute lymphocytic leukemia (Kopan and Ilagan, 2009). Brou et al. (2000) and Mumm et al. (2000) identified the Notch1 cleavage site in the NRR between Ala-1710 and Val-1711, just 13 amino acids upstream of the transmembrane domain. These studies, in combination with more recent reports, have demonstrated that ADAM10, ADAM17, and possibly other proteases recognize this cleavage site (Brou et al., 2000;
Mumm et al., 2000; Bozkulak and Weinmaster, 2009; van Tetering et al., 2009). Thus, in vivo inactivation of only ADAM10 or ADAM17 may result in a milder phenotype than Notch1 inactivation. For example, thymocyte development was altered to a lesser degree in ADAM10-deficient thymocytes compared with Notch1-deficient thymocytes generated with the same cre-expressing transgene (Wolfer et al., 2002; Tian et al., 2008).

In contrast, the phenotype of B cell-specific ADAM10 knockout mice described in this study is strikingly similar to the phenotype reported for Notch2 B cell knockouts. Although the thymocyte-specific knockout mice were generated with a different ADAM10 loxP/loxP allele, the stronger $\mathrm{B}$ cell phenotype may indicate that ADAM10 is the only protease that recognizes the Notch2 cleavage site, which is distinct from the Notch1 site previously described (Brou et al., 2000).
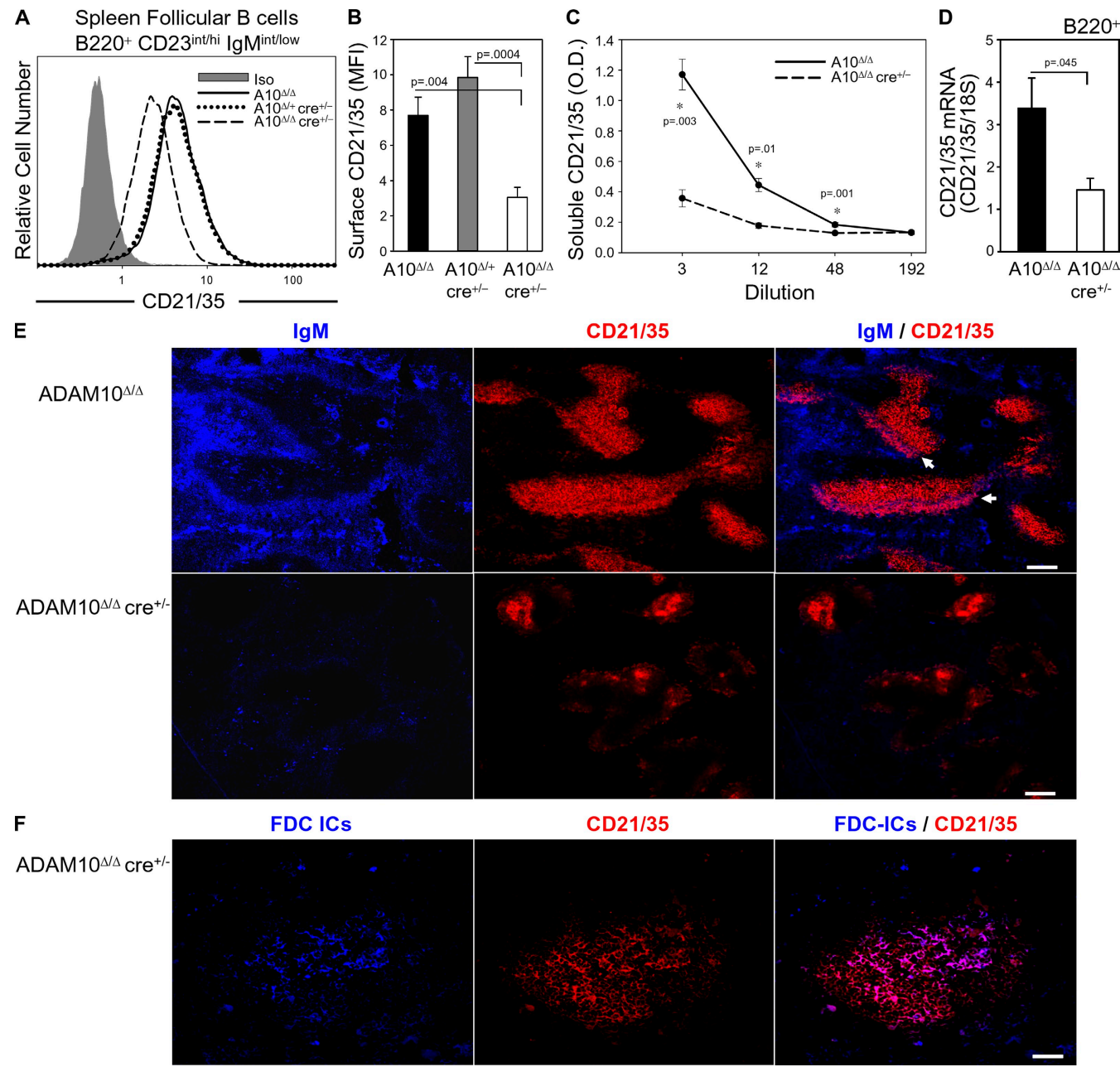

Figure 5. CD21/35 expression is reduced in ADAM10 ${ }^{\Delta / \Delta C D 19 c^{+/-}}$mice. (A) Cell-surface expression of CD21/35 on spleen F0 B cells. Data are representative of four independent experiments. (B) Quantified mean fluorescence intensity (MFI) from A. (C) Serum-soluble CD21/35 measured by ELISA ( $n=5$; data are cumulative from five independent experiments). (D) Quantitative PCR of CD21/35 mRNA expression in B220+ spleen cells relative to 18S expression ( $n=4$; data are cumulative from four independent experiments). Error bars represent the SEM between samples. (E) Immunohistochemistry of spleen follicles labeled with IgM-AMCA and CD21/35-PE. Arrows indicate MZBs with overlay staining. Bars, $100 \mu$ m. (F) Higher magnification of intense CD21/35 labeling in the ADAM $10^{\Delta / \Delta} \mathrm{Cre}^{+/-}$follicles shown in E. FDC immune complexes (ICs) are labeled with anti-IgG-AMCA. Bar, $50 \mu \mathrm{m}$. Immunohistochemistry is representative of three independent experiments. 
The effects of ADAM10 deletion on MZB development, CD21/35 expression, Dtx1 expression, and Dll1-stimulated Notch signaling clearly demonstrate ADAM10's role in Notch2 signaling. However, we do not rule out the possibility that ADAM10 may also be required for signaling through other minimally expressed Notch receptors on B cells. In fact, quantification of Hes1 and Hes 5 expression revealed a more significant impairment of Notch signaling in ADAM10null B cells than reported for Notch2-null B cells (Saito et al., 2003). This may reflect a greater purity of $\mathrm{EYFP}^{+} \mathrm{ADAM} 10-$ null B cells, or the ability of other minimally expressed Notch receptors to signal in the absence of Notch2 but not in the absence of ADAM10. Nevertheless, the effect on MZB development is clearly caused by impaired Notch 2 signaling, and contrary to studies in thymocytes, this study describes an absolute requirement for ADAM10 activity in the development of a lymphocyte subset.

Our finding that ADAM10 initiates Notch2 signaling has important implications for the treatment of Notch-related diseases. Disregulated Notch signaling underlies numerous human pathologies ranging from developmental impairments to cancer (Kopan and Ilagan, 2009). Specifically, unregulated Notch2 signaling is a defining characteristic of B cell chronic lymphocytic leukemia (B-CLL), diffuse large B cell lymphoma, and marginal zone lymphoma (Troen et al., 2008; Lee et al., 2009; Rosati et al., 2009). Although many regulators of Notch2 signaling have been described, progress in using these findings for therapeutic purposes has been restricted by a lack of understanding of signal activation. Certainly, identifying the proteinase responsible for initiating the irreversible signaling cascade represents significant progress for attempts to control Notch2-related diseases, including B-CLL.

Our finding that ADAM10 is the principal sheddase of CD23 in vivo resolves earlier data describing CD23 cleavage by multiple ADAMs in vitro (Fourie et al., 2003; Weskamp et al., 2006). Demonstration that CD23 cleavage is sensitive to hydroxamic acid inhibitors, which inhibit the proteolytic activity of ADAMs, stimulated significant progress toward identifying the sheddase (Conrad et al., 2007). Various studies have ruled out a role for ADAMs 8, 9, 12, 15, and 17 in vivo (Weskamp et al., 2006; Le Gall et al., 2009). A recent study determined that MMP-9 cleaves CD23 in LPS-treated mice (Jackson et al., 2009). However, MMP-9-dependent cleavage was not examined in naive mice, and a role for ADAM10 was not excluded. In this study, we demonstrate that deletion of ADAM10 from B cells profoundly impairs CD23 cleavage in vivo, resulting in a dramatic increase in the level of CD23 expressed on the B cell surface, and a profound reduction in $\mathrm{SCD} 23$.

This finding has important implications for the treatment of allergic and inflammatory reactions. Binding of $\operatorname{IgE}$ to CD23 on the B cell surface promotes transport and presentation of antigen associated with $\mathrm{IgE}$ immune complexes (Hjelm et al., 2008). In addition, mCD23 has been proposed as a natural repressor of IgE synthesis (Conrad et al., 2007). However, cleavage of CD23 from the cell surface may interrupt
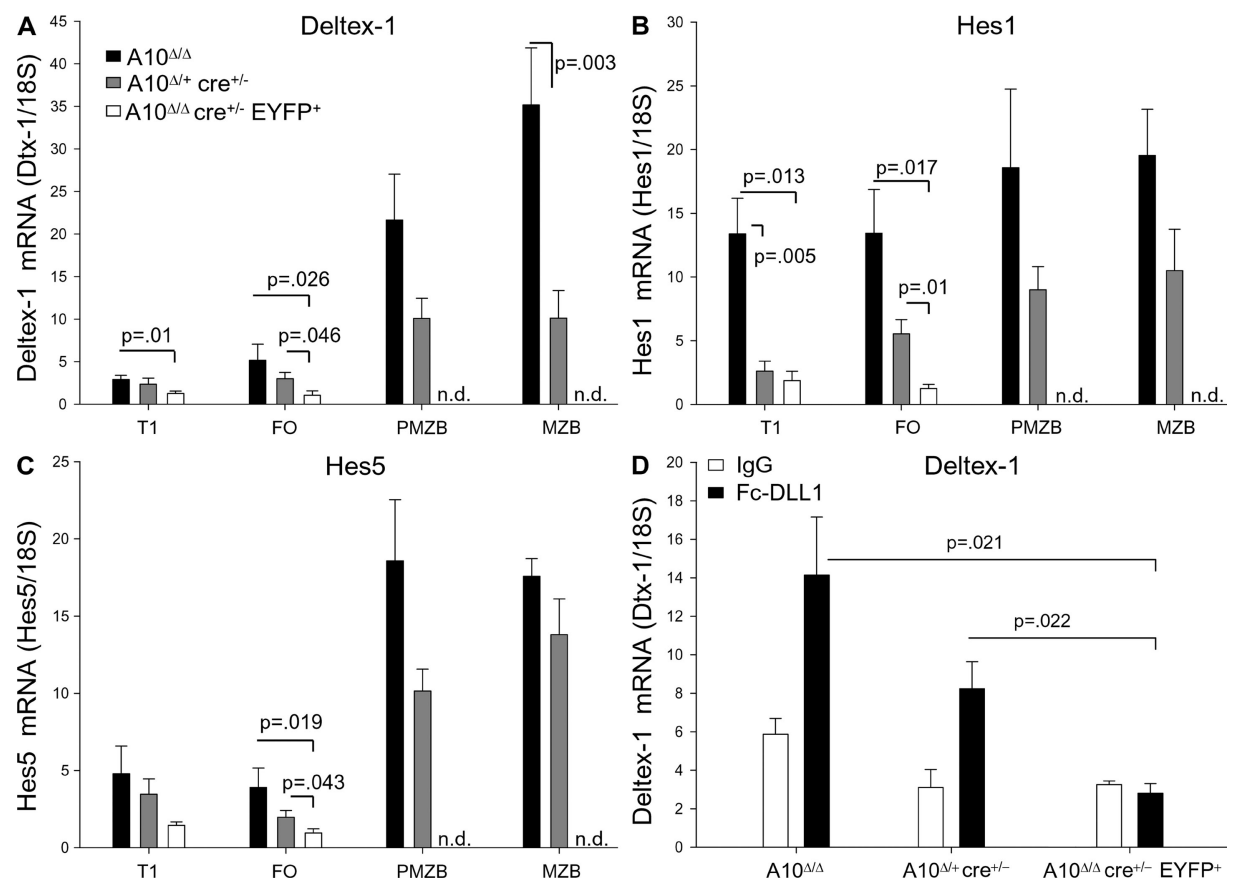

Figure 6. ADAM10 initiates Notch2 signaling. (A-C) Gene expression of targets of Notch2 signaling in primary B cells determined by quantitative real-time PCR. Data are cumulative from at least four independent experiments. T1 cells, FO cells, PMZBs, and MZBs identified as in Fig. 2 were sorted via FACS (A, $n=7 ; B, n=4 ;$ and $C, n=4)$ Expression by PMZBs and MZBs from ADAM $10^{\Delta / \Delta} \mathrm{cre}^{+/-E Y F P+}$ mice was not determined because of cell loss (Fig. 2). (D) Expression of Dtx 1 in FO B cells stimulated with CD40L and Fc-DII1 or control mouse lgG for $60 \mathrm{~h}$, with expression relative to $18 \mathrm{~S}$ expression $(n=3$; data are cumulative from three independent experiments). Error bars represent the SEM between samples. n.d., not determined. 
this negative feedback mechanism and result in elevated IgE synthesis. Additionally, the cleaved product, sCD23, is elevated in synovial fluids of patients with rheumatoid arthritis and may contribute to disease by activating monocytes (Lecoanet-Henchoz et al., 1995; Ribbens et al., 2000). Thus, inhibiting cleavage by the endogenous CD23 sheddase has been proposed as a novel therapy for controlling allergic and rheumatic disease (Conrad et al., 2007). Moreover, an increased sCD23 level in the serum of patients with B-CLL is a negative prognostic indicator for survival (Sarfati et al., 1996). Given that constitutive Notch2 signaling and CD23 cleavage in B-CLL cells are well established (Sarfati et al., 1996; Rosati et al., 2009), this study indicates that ADAM10 is a potential target for B-CLL therapy.

Given the structural similarity of many ADAMs and the highly conserved nature of sequences within proteinase domains, we were surprised to find that deletion of ADAM10 had such profound effects on CD23 cleavage and Notch2 signaling. ADAM10 shares the greatest sequence similarity with ADAM17 (Black and White, 1998). Previous studies using ADAM10 ${ }^{-/-}$MEFs have indicated considerable overlap in substrate recognition between multiple ADAMs, and especially between ADAMs 10 and 17 (Hinkle et al., 2004; Sahin et al., 2004; Le Gall et al., 2009). Although B cells also express ADAM17 (Contin et al., 2003), we found no evidence of significant compensatory mechanisms while examining primary ADAM10-null B cells or cells stimulated to enhance CD23 cleavage or Notch2 signaling. Although we did not examine ADAM17-null B cells, Li et al. (2007) demonstrated that reconstitution of $\mathrm{RAG1}^{-/-}$mice with bone marrow cells lacking the $\mathrm{Zn}$-binding domain of ADAM17 resulted in unaltered B cell development. Additionally, CD23 cleavage is not altered in B cell-specific ADAM17 knockout mice (Le Gall et al., 2009). Thus, this study reveals that substrate recognition by specific ADAMs may be more stringent in vivo than in vitro studies would predict. This indicates that development of specific ADAM inhibitors may be more efficacious than previously thought.

The requirement for ADAM10 in Notch2 signaling and CD23 cleavage has generated numerous questions about the role of ADAM10 in immune responses. MZBs respond quickly to T-independent antigens by secreting IgM, facilitate the deposition of immune complexes on FDCs by shuttling between the marginal zone and the spleen follicle, and perform a protective role in models of sepsis (Pillai et al., 2005; Cinamon et al., 2008). Thus, it is likely that these responses are impaired in ADAM10 $0^{\Delta / \Delta} \mathrm{Cre}^{+/-}$mice. Notwithstanding MZBs, Thomas et al. (2007) demonstrated that Notch signaling promotes B cell activation by enhancing $\mathrm{B}$ cell receptor and CD40 signaling. Synergy also exists between Notch and NF-kB signaling, which influences multiple B cell functions (Moran et al., 2007). Additionally, Santos et al. (2007) demonstrated that Notch1 activity, which is induced in LPS-stimulated B cells, promotes the differentiation of antibody-secreting B cells. This has stimulated interest in ADAM10's role in regulating Notch1 signaling in activated
B cells. ADAM10-null B cells also express elevated CD23 and reduced CD21/35, which also regulate antibody production (Croix et al., 1996; Payet et al., 1999). Thus, the role of ADAM10 in adaptive immune responses may be extensive and warrants further study.

In conclusion, examination of CD23 and Notch2 cleavage in B cell-specific ADAM10 knockout mice has shown that other proteases do not compensate for a lack of ADAM10 activity in vivo. This study demonstrates that ADAM10 is the primary sheddase of CD23 in vivo. Moreover, it reveals that ADAM10 critically regulates MZB lineage development by initiating Notch2 signaling.

\section{MATERIALS AND METHODS}

Mice. Generation of ADAM10 flox/flox mice on the C57BL/6J (B6) background was performed by inGenious Targeting Laboratories and is illustrated in Fig. S1. In brief, a targeting vector containing intron 8, exon 9, and intron 9 of mouse Adam 10 was inserted in the Adam 10 gene via homologous recombination. The inserted sequence contains a neomycin (Neo) cassette flanked by FRT and loxP sites for selection of embryonic stem cell clones. Once ADAM10 $0^{\text {flox } /+}$ founders with germline transmission were established, the Neo cassette was removed from the germline by mating progeny with $\mathrm{ACT}-\mathrm{FLPe}^{+/+}$transgenic mice expressing the FLP recombinase under control of the human $A C T B$ promoter. This generated ADAM10 $0^{\Delta /+}$ mice containing exon 9 flanked by loxP sites in introns 8 and 9. Crossing ADAM10 $0^{\Delta / \Delta}$ and CD19 $\mathrm{cre}^{+/+}$knockin mice generated ADAM10 ${ }^{\Delta /+} \mathrm{CD} 19 \mathrm{cre}^{+/-}$heterozygotes. ADAM10 ${ }^{\Delta / \Delta} \mathrm{CD} 19 \mathrm{cre}^{+/-}$mice were generated by crossing heterozygotes with ADAM10 $0^{\Delta / \Delta}$ mice. R26R-EYFP ${ }^{+}$mice crossed with ADAM10 ${ }^{\Delta / \Delta} \mathrm{CD} 19 \mathrm{cre}^{+/-}$mice produced ADAM10 ${ }^{\Delta / \Delta} \mathrm{CD} 19 \mathrm{cre}^{+/-} \mathrm{R} 26 \mathrm{R}-$ $\mathrm{EYFP}^{+}$mice. CD19cre ${ }^{+/+}$knockin and R26R-EYFP ${ }^{+}$transgenic mice on a C57BL/6 background were obtained from the Jackson Laboratory. CD23 transgenic and CD23 ${ }^{-/-}$mice were previously described (Yu et al., 1994; Payet et al., 1999). C57BL/6 mice were wild-type littermates of CD23 transgenics. All mouse protocols were approved by the Virginia Commonwealth University Animal Care and Use Committee.

Flow cytometry and cell sorting. Single-cell suspensions of PLN cells and splenocytes were created by disrupting inguinal, brachial, and axillary LNs and spleens between glass slides. After red blood cell lysis, filtered cells were labeled with antibodies including B220-FITC (RA3-6B2), Thy1.2-PE (30-H12), IgD-PE (11-26c.2a), CD9-PE (MZ3), CD11b-PE (M1/70), IgM-allophycocyanin (APC; RMM-1), CD1d-PerCP/Cy5.5 (1B1), CD23PE/Cy7 (B3B4), and biotinylated CD21/35 (7E9) from BioLegend; CD3PE (2C11) and CD21/35-PE (7G6) from BD; CD5-APC (53-7.3) and AA4.1-APC from eBioscience; and ADAM10-PE (FAB946) from R\&D Systems, used at $0.25 \mu \mathrm{g} / 10^{6}$ cells, and biotinylated HMN2-35 (Moriyama et al., 2008), used at $0.5 \mu \mathrm{g} / 10^{6}$ cells for $30 \mathrm{~min}$ on ice. Cells labeled with biotinylated antibodies were washed twice and stained with streptavidinenergy-coupled dye (Beckman Coulter) for $30 \mathrm{~min}$. Flow cytometric analysis was performed using an FC500 (Beckman Coulter), or a FACSCanto or FACSAria II (BD). Overlays of histograms were generated in SigmaPlot 10.0 software as line plots and smoothed using the SMOOTH transform. For FACS, T cells were depleted with CD90.2-conjugated magnetic beads (MACS; Miltenyi Biotec). The remaining $\mathrm{B} 220^{+}$or $\mathrm{EYFP}^{+} \mathrm{B}$ cell subsets were sorted with a FACSAria II according to the following criteria: FO cells, CD $23^{\text {int } / h i} C D 21^{\text {int }} \operatorname{IgM}^{\text {int }}$; PMZBs, CD $23^{\text {int } / h i} C D 21^{\text {hi }} \operatorname{IgM}^{\text {hi }}$; T1

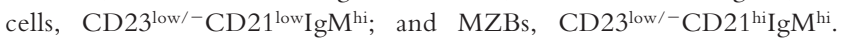
Experiments were only conducted with cell purity levels $>95 \%$.

PCR, RT-PCR, and quantitative PCR. Total RNA was extracted and purified from sorted $\mathrm{B}$ cells from mouse spleens using TRIzOL reagent (Invitrogen). Samples were treated with DNase (Takara Bio Inc.), mixed with phenol/chloroform/isoamyl alcohol solution (25:24:1; USB), and 
precipitated with ethyl alcohol. The purity of RNA was quantified by a spectrophotometer (ND-100; NanoDrop). $1 \mu \mathrm{g}$ RNA was reverse transcribed using the High Capacity cDNA RT kit (Applied Biosystems). Real-time quantitative PCR was performed with a real-time PCR machine (iQ5; Bio-Rad Laboratories). All reagents, including primers and probes for running a TaqMan quantitative PCR assay, were purchased from Applied Biosystems. TaqMan gene expression assays included Hes1:MA00468601_A1, Hes5:MA00439311_g1, Rbp-Јк:MA00770450_A1, and Deltex-1: MA00492297_A1. PCR products, labeled with 6-FAM-conjugated probes, were amplified with $18 \mathrm{~S}$ as an internal control. Reaction parameters were as follows: hold at $48^{\circ} \mathrm{C}$ for $30 \mathrm{~min}$ and hold at $95^{\circ} \mathrm{C}$ for $10 \mathrm{~min}$, followed by 40 cycles of $95^{\circ} \mathrm{C}$ for $15 \mathrm{~s}$ and $60^{\circ} \mathrm{C}$ for $60 \mathrm{~s}$. Results were analyzed with iQ5 real-time PCR software (version 2.0).

For RT-PCR analysis, RNA was reverse transcribed as described. cDNA was amplified using $2 \times$ PCR Master Mix (Promega), $4 \mu \mathrm{M}$ of forward and reverse primers, $100 \mathrm{ng}$ of cDNA template, and nuclease-free water. RT-PCR was performed using a Mycycler (Bio-Rad Laboratories) with the following conditions: initial incubation at $95^{\circ} \mathrm{C}$ for $3 \mathrm{~min}$, followed by 35 cycles of $94^{\circ} \mathrm{C}$ for $1 \mathrm{~min}, 62^{\circ} \mathrm{C}$ for $45 \mathrm{~s}$, and an extension at $72^{\circ} \mathrm{C}$ for $2 \mathrm{~min}$, and a final extension at $72^{\circ} \mathrm{C}$ for $10 \mathrm{~min}$. The PCR products with the expected molecular weights were confirmed by electrophoresis using $1.5 \%$ agarose gels. $\beta$-Actin was used as a reference control.

For analysis of cre-mediated recombination of ADAM10-exon 9, DNA was isolated using DirectPCR solution (Viagen). PCR amplification was performed using the PCR Master Mix as described for cDNA amplification. Cycling conditions were as follows: $95^{\circ} \mathrm{C}$ for $3 \mathrm{~min}$, followed by 35 cycles of $94^{\circ} \mathrm{C}$ for $1 \mathrm{~min}, 55^{\circ} \mathrm{C}$ for $1 \mathrm{~min}$, and $72^{\circ} \mathrm{C}$ for $2 \mathrm{~min}$, and a final extension at $72^{\circ} \mathrm{C}$ for $10 \mathrm{~min}$. Sequences of all primers and probes except those included in the purchased TaqMan gene expression assays described are listed in Table S1.

ELISAs. ELISAs for measuring sCD23 and soluble CD21/35 have been previously described (Weskamp et al., 2006; Hoefer et al., 2008). Mouse serum was collected via tail vein nick and separated from cells after centrifugation.

Stimulation of CD23 cleavage and Notch signaling. For CD23 cleavage, spleen FO B cells isolated by FACS were cultured $\left(10^{6}\right.$ cells $\left./ \mathrm{ml}\right)$ in the presence of $10,000 \mathrm{U} / \mathrm{ml} \mathrm{IL}-4,25 \mathrm{ng} / \mathrm{ml} \mathrm{CD} 40 \mathrm{~L}$ trimer, and $0.7 \mu \mathrm{g} / \mathrm{ml} 8$ : A3 for $24 \mathrm{~h}$. Cells were washed and restimulated with cytokines in the presence of $100 \mu \mathrm{g} / \mathrm{ml} \mathrm{C0H} 2$ or $19 \mathrm{G} 5$ for $17 \mathrm{~h}$. Levels of sCD23 in cell supernatants and mCD23 on B cells were determined by ELISA and flow cytometry, respectively. Trimeric CD40L containing a leucine zipper (LZ) motif was obtained from Amgen. Generation and purification of 19G5 and $\mathrm{COH} 2$ was previously described (Kilmon et al., 2004). 8:A3 is a monoclonal rat IgG2a antibody directed against the LZ motif of recombinant LZ-CD23, produced by injecting recombinant LZ-CD23 into rats and fusing rat splenocytes with the IR 983 cell line as previously described (Kelly et al., 1998). Purification was the same as described for 19G5. Baclovirus-expressed IL-4 was a gift from W.E. Paul (National Institutes of Health, Bethesda, MD).

For stimulated Notch signaling, spleen FO B cells isolated via FACS were cultured in the presence of $\mathrm{CD} 40 \mathrm{~L}$ and 8:A3, as described in the previous paragraph, and $10 \mu \mathrm{g} / \mathrm{ml}$ of plate-bound Fc-Dll1 (R\&D Systems) or $10 \mu \mathrm{g} / \mathrm{ml}$ of mouse IgG (SouthernBiotech) for 36, 60, or $84 \mathrm{~h}$. Expression of Dtx1, Hes1, and Hes5 was determined by quantitative PCR.

Immunofluorescence and confocal microscopy. Spleens were frozen on dry ice in OCT compound (Tissue-Tek; Sakura). Serial 10- $\mu \mathrm{m}$ sections were cut from frozen blocks using a cryostat (Frigocut 2800E; Jung), fixed in absolute acetone, and air dried. Sections were blocked with 10\% BSA in PBS to prevent background staining and then washed and incubated for $60 \mathrm{~min}$ with different combinations of $2 \mathrm{mg} / \mathrm{ml}$ anti-mouse CD169-FITC (MOMA-1; AbD Serotec), IgD-PE (11-26), CD23-PE (2G8; SouthernBiotech), goat anti-mouse IgM-aminomethylcoumarin acetate (AMCA), goat anti-mouse IgG-AMCA (Jackson ImmunoResearch Laboratories, Inc.), or CD21/35-PE (7G6; BD). Sections were washed, mounted with antifade mounting medium (Vectashield; Vector Laboratories), cover slipped, and examined with a confocal laser scanning microscope (TCS-SP2 AOBS; Leica) fitted with an oil Plan-Apochromat $40 \times$ objective. Three lasers were used: blue diode $(405 \mathrm{~nm})$ for AMCA, argon $(488 \mathrm{~nm})$ for FITC, and $\mathrm{HeNe}$ $(543 \mathrm{~nm})$ for PE. Parameters were adjusted to scan at a $512 \times 512$ pixel density and an 8-bit pixel depth. Emissions were recorded in three separate channels. Digital images were captured, overlaid, and processed with the Confocal and LCS Lite programs (Leica).

Statistical analysis. p-values were calculated using unpaired two-tailed Student's $t$ tests. Error bars represent the SEM between samples.

Online supplemental material. Fig. S1 is a schematic of the ADAM10 ${ }^{\Delta}$ allele. Fig. S2 shows that CD19cre-mediated recombination of Adam10 is B cell specific. Fig. S3 demonstrates that the levels of pro-/pre-B cells, immature B cells, and total spleen B cells are not altered in ADAM10 $0^{\Delta / \Delta}$ $\mathrm{CD} 19 \mathrm{cre}^{+/-}$mice. Fig. S4 shows that B1 cell development is not affected by ADAM10 deletion. Fig. S5 shows the percentage of T2 $\mathrm{B}$ cells in the spleens of ADAM10 $0^{\Delta / \Delta} \mathrm{cre}^{+/-} \mathrm{EYFP}^{+}$and control mice. Fig. S6 shows that membrane CD23 levels are also significantly elevated on total spleen and PLN B cells, whereas the level of CD23 mRNA is unaffected. Fig. S7 shows that ADAM10 and Notch2 are preferentially expressed on PMZBs and MZBs, and ADAM10 deletion does not alter surface expression of Notch2. Fig. S8 shows that CD21/35 surface expression is also significantly decreased on PLN B cells. Table S1 provides primer and probe sequences. Online supplemental material is available at http://www.jem .org/cgi/content/full/jem.20091990/DC1.

We thank S. Norton, S. Saleem, and D. Purkall for technical help; W. Paul for recombinant mouse IL-4; and S. Barbour and S. Norton for comments on the manuscript.

This work was supported by the National Institutes of Health (grants R01Al18697 and U19Al077435 to D.H. Conrad, grant DK63363 to P.J. Dempsey, and grant R03CA129579 to H.C. Crawford), the Crohn's and Colitis Foundation of America (P.J. Dempsey), the Veteran's Administration Merit Award (H.C. Crawford), the Polish Ministry of Scientific Research (grant N401 003635 to J. Cichy), and the American Heart Association (grant 0815066E to D.R. Gibb). Microscopy was performed at the Virginia Commonwealth University Department of Neurobiology and Anatomy Microscopy Facility, and was supported by the National Institutes of Health-National Institute of Neurological Disorders and Stroke Center (core grant 5P30NS047463).

The authors have no conflicting financial interests.

Submitted: 14 September 2009

Accepted: 12 January 2010

\section{REFERENCES}

Black, R.A., and J.M. White. 1998. ADAMs: focus on the protease domain. Curr. Opin. Cell Biol. 10:654-659. doi:10.1016/S0955-0674(98)80042-2

Blobel, C.P. 2005. ADAMs: key components in EGFR signalling and development. Nat. Rev. Mol. Cell Biol. 6:32-43. doi:10.1038/nrm1548

Bozkulak, E.C., and G. Weinmaster. 2009. Selective use of ADAM10 and ADAM17 in activation of Notch1 signaling. Mol. Cell. Biol. 29:5679-5695. doi:10.1128/MCB.00406-09

Brou, C., F. Logeat, N. Gupta, C. Bessia, O. LeBail, J.R. Doedens, A. Cumano, P. Roux, R.A. Black, and A. Israël. 2000. A novel proteolytic cleavage involved in Notch signaling: the role of the disintegrin-metalloprotease TACE. Mol. Cell. 5:207-216. doi:10.1016/S1097-2765(00)80417-7

Cinamon, G., M.A. Zachariah, O.M. Lam, F.W. Foss Jr., and J.G. Cyster. 2008. Follicular shuttling of marginal zone B cells facilitates antigen transport. Nat. Immunol. 9:54-62. doi:10.1038/ni1542

Conrad, D.H., J.W. Ford, J.L. Sturgill, and D.R. Gibb. 2007. CD23: an overlooked regulator of allergic disease. Curr. Allergy Asthma Rep. 7:331-337. doi:10.1007/s11882-007-0050-y

Contin, C., V. Pitard, T. Itai, S. Nagata, J.F. Moreau, and J. DéchanetMerville. 2003. Membrane-anchored CD40 is processed by the tumor necrosis factor-alpha-converting enzyme. Implications for CD40 signaling. J. Biol. Chem. 278:32801-32809. doi:10.1074/jbc.M209993200 
Crawford, H.C., P.J. Dempsey, G. Brown, L. Adam, and M.L. Moss. 2009. ADAM10 as a therapeutic target for cancer and inflammation. Curr. Pharm. Des. 15:2288-2299. doi:10.2174/138161209788682442

Croix, D.A., J.M. Ahearn, A.M. Rosengard, S. Han, G. Kelsoe, M. Ma, and M.C. Carroll. 1996. Antibody response to a T-dependent antigen requires B cell expression of complement receptors. J. Exp. Med. 183:1857-1864. doi:10.1084/jem.183.4.1857

Ford, J.W., M.A. Kilmon, K.M. Haas, A.E. Shelburne, Y. Chan-Li, and D.H Conrad. 2006. In vivo murine CD23 destabilization enhances CD23 shedding and IgE synthesis. Cell. Immunol. 243:107-117. doi:10.1016/ j.cellimm.2007.01.004

Fourie, A.M., F. Coles, V. Moreno, and L. Karlsson. 2003. Catalytic activity of ADAM8, ADAM15, and MDC-L (ADAM28) on synthetic peptide substrates and in ectodomain cleavage of CD23. J. Biol. Chem. 278:30469-30477. doi:10.1074/jbc.M213157200

Gould, H.J., and B.J. Sutton. 2008. IgE in allergy and asthma today, Nat. Rev. Immunol. 8:205-217. doi:10.1038/nri2273

Hamada, Y., Y. Kadokawa, M. Okabe, M. Ikawa, J.R. Coleman, and Y. Tsujimoto. 1999. Mutation in ankyrin repeats of the mouse Notch2 gene induces early embryonic lethality. Development. 126:3415-3424.

Hartmann, D., B. de Strooper, L. Serneels, K. Craessaerts, A. Herreman, W. Annaert, L. Umans, T. Lübke, A. Lena Illert, K. von Figura, and P. Saftig. 2002. The disintegrin/metalloprotease ADAM 10 is essential for Notch signalling but not for alpha-secretase activity in fibroblasts. Hum. Mol. Genet. 11:2615-2624. doi:10.1093/hmg/11.21.2615

Hinkle, C.L., S.W. Sunnarborg, D. Loiselle, C.E. Parker, M. Stevenson, W.E. Russell, and D.C. Lee. 2004. Selective roles for tumor necrosis factor alpha-converting enzyme/ADAM17 in the shedding of the epidermal growth factor receptor ligand family: the juxtamembrane stalk determines cleavage efficiency. J. Biol. Chem. 279:24179-24188. doi:10.1074/jbc.M312141200

Hjelm, F., M.C. Karlsson, and B. Heyman. 2008. A novel B cell-mediated transport of IgE-immune complexes to the follicle of the spleen. J. Immunol. 180:6604-6610.

Hoefer, M.M., A. Aichem, A.M. Knight, and H. Illges. 2008. Modulation of murine complement receptor type 2 (CR2/CD21) ectodomain shedding by its cytoplasmic domain. Mol. Immunol. 45:2127-2137. doi:10.1016/ j.molimm.2007.12.015

Hozumi, K., N. Negishi, D. Suzuki, N. Abe, Y. Sotomaru, N. Tamaoki, C. Mailhos, D. Ish-Horowicz, S. Habu, and M.J. Owen. 2004. Delta-like 1 is necessary for the generation of marginal zone $\mathrm{B}$ cells but not $\mathrm{T}$ cells in vivo. Nat. Immunol. 5:638-644. doi:10.1038/ni1075

Jackson, L., C.T. Cady, and J.C. Cambier. 2009. TLR4-mediated signaling induces MMP9-dependent cleavage of B cell surface CD23. J. Immunol. 183:2585-2592. doi:10.4049/jimmunol.0803660

Kelly, A.E., B.-H. Chen, E.C. Woodward, and D.H. Conrad. 1998. Production of a chimeric form of CD23 that is oligomeric and blocks IgE binding to the Fc epsilonRI. J. Immunol. 161:6696-6704.

Kilmon, M.A., A.E. Shelburne, Y. Chan-Li, K.L. Holmes, and D.H. Conrad. 2004. CD23 trimers are preassociated on the cell surface even in the absence of its ligand, IgE. J. Immunol. 172:1065-1073.

Kopan, R., and M.X. Ilagan. 2009. The canonical Notch signaling pathway: unfolding the activation mechanism. Cell. 137:216-233. doi:10.1016/ j.cell.2009.03.045

Lecoanet-Henchoz, S., J.-F. Gauchat, J.-P. Aubry, P. Graber, P. Life, N. Paul-Eugene, B. Ferrua, A.L. Corbi, B. Dugas, C. Plater-Zyberk, and J.-Y. Bonnefoy. 1995. CD23 regulates monocyte activation through a novel interaction with the adhesion molecules CD11bCD18 and CD11c-CD18. Immunity. 3:119-125. doi:10.1016/ 1074-7613(95)90164-7

Lee, S.Y., K. Kumano, K. Nakazaki, M. Sanada, A. Matsumoto, G. Yamamoto, Y. Nannya, R. Suzuki, S. Ota, Y. Ota, et al. 2009. Gain-of-function mutations and copy number increases of Notch2 in diffuse large B-cell lymphoma. Cancer Sci. 100:920-926. doi:10.1111/ j.1349-7006.2009.01130.x

Le Gall, S.M., P. Bobe, K. Reiss, K. Horiuchi, X.D. Niu, D. Lundell, D.R. Gibb, D. Conrad, P. Saftig, and C.P. Blobel. 2009. ADAMs 10 and 17 represent differentially regulated components of a general shedding machinery for membrane proteins such as transforming growth factor alpha, L-selectin, and tumor necrosis factor alpha. Mol. Biol. Cell. 20: 1785-1794. doi:10.1091/mbc.E08-11-1135

Lemieux, G.A., F. Blumenkron, N. Yeung, P. Zhou, J. Williams, A.C. Grammer, R. Petrovich, P.E. Lipsky, M.L. Moss, and Z. Werb. 2007. The low affinity $\operatorname{IgE}$ receptor (CD23) is cleaved by the metalloproteinase ADAM10. J. Biol. Chem. 282:14836-14844. doi:10.1074/jbc. M608414200

Li, N., K. Boyd, P.J. Dempsey, and D.A. Vignali. 2007. Non-cell autonomous expression of TNF-alpha-converting enzyme ADAM17 is required for normal lymphocyte development. J. Immunol. 178:4214-4221.

Makar, K.W., D. Ulgiati, J. Hagman, and V.M. Holers. 2001. A site in the complement receptor $2(\mathrm{CR} 2 / \mathrm{CD} 21)$ silencer is necessary for lineage specific transcriptional regulation. Int. Immunol. 13:657-664. doi:10.1093/ intimm/13.5.657

Manilay, J.O., A.C. Anderson, C. Kang, and E.A. Robey. 2005. Impairment of thymocyte development by dominant-negative Kuzbanian (ADAM-10) is rescued by the Notch ligand, delta-1. J. Immunol. 174 6732-6741.

Moran, S.T., A. Cariappa, H. Liu, B. Muir, D. Sgroi, C. Boboila, and S. Pillai. 2007. Synergism between NF-kappa B1/p50 and Notch2 during the development of marginal zone B lymphocytes. J. Immunol. 179:195-200.

Moriyama, Y., C. Sekine, A. Koyanagi, N. Koyama, H. Ogata, S. Chiba, S. Hirose, K. Okumura, and H. Yagita. 2008. Delta-like 1 is essential for the maintenance of marginal zone B cells in normal mice but not in autoimmune mice. Int. Immunol. 20:763-773. doi:10.1093/intimm/dxn034

Mumm, J.S., E.H. Schroeter, M.T. Saxena, A. Griesemer, X. Tian, D.J. Pan, W.J. Ray, and R. Kopan. 2000. A ligand-induced extracellular cleavage regulates gamma-secretase-like proteolytic activation of Notch1. Mol. Cell. 5:197-206. doi:10.1016/S1097-2765(00)80416-5

Payet, M.E., E.C. Woodward, and D.H. Conrad. 1999. Humoral response suppression observed with CD23 transgenics. J. Immunol. 163:217-223.

Pillai, S., A. Cariappa, and S.T. Moran. 2005. Marginal zone B cells. Annu. Rev. Immunol. 23:161-196. doi:10.1146/annurev.immunol.23 .021704 .115728

Radtke, F., A. Wilson, S.J. Mancini, and H.R. MacDonald. 2004. Notch regulation of lymphocyte development and function. Nat. Immunol. 5:247-253. doi:10.1038/ni1045

Ribbens, C., V. Bonnet, M.J. Kaiser, B. Andre, O. Kaye, N. Franchimont, D. de Groote, Y. Beguin, and M.G. Malaise. 2000. Increased synovial fluid levels of soluble CD23 are associated with an erosive status in rheumatoid arthritis (RA). Clin. Exp. Immunol. 120:194-199. doi:10.1046/ j.1365-2249.2000.01198.x

Rickert, R.C., J. Roes, and K. Rajewsky. 1997. B lymphocyte-specific, Cre-mediated mutagenesis in mice. Nucleic Acids Res. 25:1317-1318. doi:10.1093/nar/25.6.1317

Rosati, E., R. Sabatini, G. Rampino, A. Tabilio, M. Di Ianni, K. Fettucciari, A. Bartoli, S. Coaccioli, I. Screpanti, and P. Marconi. 2009. Constitutively activated Notch signaling is involved in survival and apoptosis resistance of B-CLL cells. Blood. 113:856-865. doi:10.1182/blood-2008-02-139725

Sahin, U., G. Weskamp, K. Kelly, H.M. Zhou, S. Higashiyama, J. Peschon, D. Hartmann, P. Saftig, and C.P. Blobel. 2004. Distinct roles for ADAM10 and ADAM17 in ectodomain shedding of six EGFR ligands. J. Cell Biol. 164:769-779. doi:10.1083/jcb.200307137

Saito, T., S. Chiba, M. Ichikawa, A. Kunisato, T. Asai, K. Shimizu, T. Yamaguchi, G. Yamamoto, S. Seo, K. Kumano, et al. 2003. Notch2 is preferentially expressed in mature B cells and indispensable for marginal zone B lineage development. Immunity. 18:675-685. doi:10.1016/ S1074-7613(03)00111-0

Santos, M.A., L.M. Sarmento, M. Rebelo, A.A. Doce, I. Maillard, A Dumortier, H. Neves, F. Radtke, W.S. Pear, L. Parreira, and J. Demengeot. 2007. Notch1 engagement by Delta-like-1 promotes differentiation of B lymphocytes to antibody-secreting cells. Proc. Natl. Acad. Sci. USA. 104:15454-15459. doi:10.1073/pnas.0702891104

Sarfati, M., S. Chevret, C. Chastang, G. Biron, P. Stryckmans, G. Delespesse, J.L. Binet, H. Merle-Beral, and D. Bron. 1996. Prognostic importance of serum soluble CD23 level in chronic lymphocytic leukemia. Blood. 88:4259-4264. 
Schulte, M., K. Reiss, M. Lettau, T. Maretzky, A. Ludwig, D. Hartmann, B. de Strooper, O. Janssen, and P. Saftig. 2007. ADAM10 regulates FasL cell surface expression and modulates FasL-induced cytotoxicity and activation-induced cell death. Cell Death Differ. 14:1040-1049.

Srinivas, S., T. Watanabe, C.S. Lin, C.M. William, Y. Tanabe, T.M. Jessell, and F. Costantini. 2001. Cre reporter strains produced by targeted insertion of EYFP and ECFP into the ROSA26 locus. BMC Dev. Biol. 1:4. doi:10.1186/1471-213X-1-4

Strobl, L.J., H. Höfelmayr, G. Marschall, M. Brielmeier, G.W. Bornkamm, and U. Zimber-Strobl. 2000. Activated Notch1 modulates gene expression in B cells similarly to Epstein-Barr viral nuclear antigen 2. J. Virol. 74:1727-1735. doi:10.1128/JVI.74.4.1727-1735.2000

Swiatek, P.J., C.E. Lindsell, F.F. del Amo, G. Weinmaster, and T. Gridley. 1994. Notch1 is essential for postimplantation development in mice. Genes Dev. 8:707-719. doi:10.1101/gad.8.6.707

Tanigaki, K., and T. Honjo. 2007. Regulation of lymphocyte development by Notch signaling. Nat. Immunol. 8:451-456. doi:10.1038/ni1453

Tanigaki, K., H. Han, N. Yamamoto, K. Tashiro, M. Ikegawa, K. Kuroda, A. Suzuki, T. Nakano, and T. Honjo. 2002. Notch-RBP-J signaling is involved in cell fate determination of marginal zone B cells. Nat. Immunol. 3:443-450. doi:10.1038/ni793

Thomas, M., M. Calamito, B. Srivastava, I. Maillard, W.S. Pear, andD. Allman. 2007. Notch activity synergizes with B-cell-receptor and CD40 signaling to enhance B-cell activation. Blood. 109:3342-3350. doi:10.1182/ blood-2006-09-046698
Tian, L., X. Wu, C. Chi, M. Han, T. Xu, and Y. Zhuang. 2008. ADAM10 is essential for proteolytic activation of Notch during thymocyte development. Int. Immunol. 20:1181-1187. doi:10.1093/intimm/dxn076

Troen, G., I. Wlodarska, A. Warsame, S. Hernández Llodrà, C. De Wolf-Peeters, and J. Delabie. 2008. NOTCH2 mutations in marginal zone lymphoma. Haematologica. 93:1107-1109. doi:10.3324/haematol .11635

van Tetering, G., P. van Diest, I. Verlaan, E. van der Wall, R. Kopan, and M. Vooijs. 2009. Metalloprotease ADAM10 is required for Notch1 site 2 cleavage. J. Biol. Chem. 284:31018-31027. doi:10.1074/jbc .M109.006775

Weskamp, G., J.W. Ford, J. Sturgill, S. Martin, A.J. Docherty, S. Swendeman, N. Broadway, D. Hartmann, P. Saftig, S. Umland, et al. 2006. ADAM10 is a principal 'sheddase' of the low-affinity immunoglobulin E receptor CD23. Nat. Immunol. 7:1293-1298. doi:10.1038/ni1399

Wolfer, A., A. Wilson, M. Nemir, H.R. MacDonald, and F. Radtke. 2002 Inactivation of Notch1 impairs VDJbeta rearrangement and allows pre-TCR-independent survival of early alpha beta lineage thymocytes. Immunity. 16:869-879. doi:10.1016/S1074-7613(02)00330-8

Yoon, S.O., X. Zhang, P. Berner, B. Blom, and Y.S. Choi. 2009. Notch ligands expressed by follicular dendritic cells protect germinal center B cells from apoptosis. J. Immunol. 183:352-358. doi:10.4049/jimmunol.0803183

Yu, P., M. Kosco-Vilbois, M. Richards, G. Köhler, M.C. Lamers, and G. Kohler. 1994. Negative feedback regulation of $\operatorname{IgE}$ synthesis by murine CD23. Nature. 369:753-756. doi:10.1038/369753a0 